\title{
Informational Content of Open-to-Close Stock Returns
}

\author{
Andrey Kudryavtsev *
}

\begin{abstract}
:
In the present study, I explore interday correlations between open-to-close and opening stock returns. Employing intraday price data on all the stocks that were S\&P 500 Index constituents during the period from 1993 to 2013, I find that stock returns in opening trading sessions systematically tend to be higher following days with relatively low (either negative, or lower than the same day's market) open-toclose returns. Moreover, I explicitly document the tendency of opening stock returns to be reversed (to change their sign) following previous day's open-to-close returns. This kind of price behaviour seems to contradict stock market efficiency, and may be potentially interpreted as stock price 'corrections' following their 'deviations' from the underlying values caused by noise trading during the continuous trading sessions. Based on this finding, for the sampling period, I construct two different daily-adjusted investment portfolios based on the opening trading sessions and involving a long position in the stocks on the days when their opening returns are expected to be high and a short position in the stocks on the days when their opening returns are expected to be low. Both portfolios are found to yield significantly positive returns, even after accounting for trading commissions, providing an evidence for practical applicability of the documented pattern in opening stock prices.
\end{abstract}

Key words: Opening Returns; Open-to-Close Returns; Stock Price Reversals.

JEL Classifications: G11, G14, G19.

\section{Introduction}

One of the most visible stylized facts in empirical finance is the autocorrelation of stock returns at fixed intervals. This autocorrelation presents a challenge to the main models in continuous-time finance, which rely on some form of the random walk hypothesis and argue that financial markets are more or less efficient. Several studies suggest that the gradual incorporation of market-wide information may cause serial correlation in short-term stock returns (e.g., Lo - MacKinlay, 1990, Sias - Starks, 1997, Chordia - Swaminathan, 2000). Other potential explanations for stock return autocorrelations include, but are not limited to, bid-ask bounce (e.g., Rhee - Wang, 1997); partial price adjustment, i.e. the observation that trade takes place at prices that do not fully reflect the information possessed by traders (e.g., Campbell et al., 1997); and the time-varying risk premium (e.g., Anderson, 2006).

Dr. Andrey Kudryavtsev, Ph.D. - Senior Lecturer; Economics and Management Department, The Max Stern Yezreel Valley Academic College, Emek Yezreel 19300, Israel, <andreyk@yvc.ac.il>. 
Over the last years, the focus of this literature has shifted to intraday patterns in stock returns. Blandon (2007) shows that while close-to-close stock returns are highly autocorrelated, daily returns calculated on an open-to-close basis do not exhibit significant levels of autocorrelation. Amihud and Mendelson (1987) and Stoll and Whaley (1990) report that the interday stock returns computed using open-to-open prices have greater variance and show more evidence of reversals than comparable returns computed from close-to-close prices. A long-standing literature on intraday stock price patterns identifies the distinct U-shaped return and return volatility pattern over the trading day (e.g., Harris, 1986, Pagano et al., 2008). In other words, these studies indicate that average stock returns and return volatilities tend to be higher at the beginning and at the end of the trading day.

Several recent studies detect interday correlations between different intraday return measures. Kudryavtsev (2012) finds that daily returns of given stocks tend to be higher following the days when the stocks' upside volatility measures are higher than their downside volatility measures. Kudryavtsev (2013) documents that daily stock returns tend to be higher following the days with relatively large high-to-close price changes (end-of-the-day price decreases), and lower following the days with relatively large low-to-close price changes (end-of-the-day price increases). These findings are interpreted as reversals following stock price overreactions to information.

The main goal of this study is to establish if there also exist stock price reversals following some "regular", rather than extreme, price changes. In this context, I expect short-term stock price reversals to follow previous days' tendencies. I analyse intraday price data on all the constituents of S\&P 500 Index over the period from 1993 to 2013, and find supporting evidence for my research hypothesis. Employing open-to-close stock returns as a proxy for intraday stock price tendencies, and the next trading day's opening returns, as a measure of potential interday reversals ${ }^{1}$, I document that opening returns tend to be higher following the days with relatively low (either negative, or lower than the same day's market) open-to-close returns. Based on these findings, I construct two different daily-adjusted portfolios involving a long (short) position in the opening session in the stocks on the days when, according to the findings, their opening returns are expected to be high (low), and demonstrate that the returns on these portfolios are significantly positive.

The rest of the paper is structured as follows: In Section 2, I describe the data sample. Section 3 presents the research hypothesis and the results, including the description of the investment strategies and their performance measures. Section 4 concludes.

1 The focus on the next days' opening sessions as potential "reversal periods" is motivated by the short-time nature of the reversals, in general, and by the observation (e.g., Harris, 1986) that the predominant portion of stock price moves takes place within the first minutes of trading. 


\section{Data description}

For the purposes of present research, I employ daily opening and closing prices of all the stocks that were making up the S\&P 500 Index during the period from January 4, 1993 to December 31, 2013 (overall, 5,289 trading days). In other words, for each of the 5,289 trading days in my sampling period, I use the prices of 500 stocks, which, at that moment, were making up the Index. The prices are adjusted to dividend payments and stock splits. For each stock i in the sample and for each trading day $t$, except for the first day of the sampling period, I calculate:

- Stock's opening return $\left(R_{O, i t}\right)$, i.e., stock price's change from last day's closing price to today's opening price, as

$$
R_{O, i t}=\frac{P_{O, i t}}{P_{C, i t-1}}-1
$$

Where $R_{O, i t}$ is stock, i's opening return on day t; $P_{O, i t}$ is stock i's opening price on day $\mathrm{t}$; and $P_{C, i t-1}$ is stock i's closing price on day $\mathrm{t}-1$. and

- Stock's open-to-close return $\left(R_{O-C, i t}\right)$, i.e., stock price's change from today's opening price to today's closing price, as:

$$
R_{O-C, i t}=\frac{P_{C, i t}}{P_{O, i t}}-1
$$

Where $R_{O-C, i t}$ is stock $i$ 's open-to-close return on day $t$.

Table 1 comprises some basic descriptive statistics of the opening and the open-toclose returns for the stocks making up the sample. First of all, the sample consists of 884 stocks that served as constituents of the S\&P 500 at certain stages of the sampling period, with the average of 2,992 trading days (almost 12 years) for each of the stocks. 681 (642) out of 886 stocks show positive mean (median) opening returns during the sampling period, and the average of the means (medians) equals $0.019 \%(0.013 \%)$. Interestingly, the latter figures are higher than the respective ones of $0.013 \%(0.008 \%)$ for the open-to-close stock returns. Consistently, only 596 (547) out of 884 stocks have positive mean (median) open-to-close returns during the same period, and for 628 (71.04 \% of the sample) stocks, mean opening returns are higher than mean open-to-close returns. These results seem in line with the U-shaped pattern of intraday returns (Wood et al., 1985, Harris, 1986, Jain Joh, 1988, Pagano et al., 2008). At the same time, opening returns are less volatile than open-to-close returns, with individual stock returns' standard deviations averaging $0.652 \%$ and $1.108 \%$, respectively. 


\section{Tab. 1: Descriptive statistics of sample stocks' opening and open-to-close returns}

\begin{tabular}{lcc}
\hline \multicolumn{1}{c}{ Statistics } & \multicolumn{2}{c}{$\begin{array}{c}\text { Average over sample stocks } \\
\text { Open-to-close } \\
\text { returns }\end{array}$} \\
\hline Mean return, in \% & 0.019 & 0.013 \\
Number (Percent) of positive mean returns & $681(77.04)$ & $596(67.42)$ \\
Median return, \% & 0.013 & 0.008 \\
Number (Percent) of positive median returns & $642(72.62)$ & $547(61.88)$ \\
Standard deviation, in \% & 0.652 & 1.108 \\
Number of stocks in the sample & & 884 \\
Number of trading days for the stocks & & 2992 \\
Number (Percent) of stocks with mean & & \\
opening returns higher than mean open-to- & & \\
close returns & & \\
\hline
\end{tabular}

Source: Authors computation from www.finance.yahoo.com.

\section{Research hypothesis and results}

\subsection{Effect of the open-to-close returns on the next day's opening returns}

Wide strand of financial literature deals with stock return autocorrelations. Several studies explicitly concentrate on the effect of the end-of-the-day significant ('extreme') stock price moves on the subsequent days' returns, and document stock price reversals (e.g., Kudryavtsev, 2012, 2013). In this study, I make an effort to establish if there exist also interday stock price reversals following some 'regular', rather than extreme, price changes. Namely, I test the following hypothesis:

Hypothesis 1: Relatively high (low) open-to-close returns lead to relatively low (high) opening returns on the next trading day.

As a preliminary way of testing for the existence of interday reversals in opening stock returns, for each of the sample stocks, I calculate correlation coefficients between the opening returns and the lagged (previous trading day's) open-to-close returns. Table 2 comprises the results and demonstrates that the average correlation coefficient over the sample stocks equals to -0.065 , and that for 778 out of 884 sample stocks, the correlations coefficients are negative, 498 of them being statistically significant. These findings provide an initial support for the existence of reversals in opening returns with respect to previous day's open-to-close returns. 


\section{Tab. 2: Interday correlations between opening and open-to-close stock returns}

\begin{tabular}{lc}
\hline \multicolumn{1}{c}{ Statistics } & $\begin{array}{c}\text { Correlation coefficients between } \\
R_{O, i t}\end{array}$ \\
& and $R_{O-C, i t-1}$ \\
\hline Average over sample stocks & -0.065 \\
Number (Percent) of positive & $106(11.99)$ \\
Number of significantly (p<0.05) positive & 12 \\
Number (Percent) of negative & $778(88.01)$ \\
Number of significantly (p<0.05) negative & 498 \\
\hline
\end{tabular}

Source: Authors computation from www.finance.yahoo.com.

At the next stage, I proceed to testing Hypothesis 1. As the most obvious proxy for the relatively high or low open-to-close stock returns, I employ their sign. Table $3 \mathrm{a}$ concentrates the basic statistics of the sample stocks' mean opening returns, separately, following the days with positive $\left(R_{O-C, i t-1}>0\right)$ and non-positive $\left(R_{O-C, i t-1} \leq 0\right)$ open-to-close returns, and of the respective return differences. The results corroborate my research hypothesis. Mean opening returns for the stocks with $R_{O-C, i t-1}>0$ and $R_{O-C, i t-1} \leq 0$ are $-0.01 \%$ and $0.054 \%$, respectively (the difference between them is $-0.066 \%$ ). For 780 out of 884 stocks, the mean opening return differences are negative, 388 of them being statistically significant at the $5 \%$ level, while only 2 out of the 104 opposite-sign (positive) differences are significant. ${ }^{3}$

\section{Tab. 3a: Opening stock returns following the days with positive and non- positive open-to-close returns: Total sample}

\begin{tabular}{lccc}
\hline \multirow{2}{*}{ Statistics } & \multicolumn{3}{c}{ Mean opening returns, for the days when: } \\
& $R_{O-C, i t-1}>0$ & $R_{O-C, i t-1} \leq 0$ & Difference \\
\hline Average over sample stocks, in \% & -0.012 & 0.054 & -0.066 \\
Number (Percent) of positive & $378(42.76)$ & $792(89.59)$ & $104(11.76)$ \\
Number of significantly (p<0.05) positive & 32 & 298 & 2 \\
Number (Percent) of negative & $506(57.24)$ & $92(10.41)$ & $780(88.24)$ \\
Number of significantly (p<0.05) negative & 149 & 10 & 388 \\
\hline
\end{tabular}

Source: Authors computation from www.finance.yahoo.com.

2 These results indicate a tendency of opening stock returns to be reversed (to change their sign) following previous day's open-to-close returns.

3 In order to test if the results are consistent for the entire sample period, I have repeated the analysis for three roughly equal subperiods (1993-1999; 2000-2006; 2007-2013). Alternatively, I have divided the sample, by years, in two subsamples according to the general market tendency of the respective year (as a proxy for bull and bear markets). The results for all the subperiods and the subsamples are qualitatively similar to those presented in Table $3 \mathrm{a}$ and are available upon request from the author. 
Furthermore, in order to test if the findings reported earlier in this Subsection are driven by overnight stock price reversals following 'regular' rather than 'extreme' stock price changes during the continuous trading sessions (as in Kudryavtsev (2013), who shows that daily stock returns tend to be higher following the days with relatively large high-to-close price differences and lower following the days with relatively large low-to-close price differences), I repeat the analysis presented in Table 3a excluding from the sample the $10 \%$ highest and the $10 \%$ lowest open-to-close returns for each given trading day. In other words, I do not include opening stock returns for the stocks that during the previous day's continuous trading session experienced 'extreme' (either positive or negative) price moves, in the calculation of the respective mean opening returns. Table $3 \mathrm{~b}$ reports the results, which are qualitatively very similar to those presented in Table $3 \mathrm{a}$. Thus, interday reversals in the opening trading sessions appear not only after large stock price changes during the continuous trading sessions, but also after moderate ones.

\section{Tab. 3b: Opening stock returns following the days with positive and non- positive open-to-close returns: $10 \%$ highest and $10 \%$ lowest open-to-close returns excluded}

\begin{tabular}{lccc}
\hline \multicolumn{1}{c}{ Statistics } & \multicolumn{3}{c}{ Mean opening returns, for the days when: } \\
& $R_{O-C, i t-1}>0$ & $R_{O-C, i t-1} \leq 0$ & Difference \\
\hline Average over sample stocks, in $\%$ & -0.011 & 0.053 & -0.064 \\
Number (Percent) of positive & $379(42.87)$ & $789(89.25)$ & $106(11.99)$ \\
Number of significantly (p<0.05) positive & 31 & 290 & 2 \\
Number (Percent) of negative & $505(57.13)$ & $95(10.75)$ & $778(88.01)$ \\
Number of significantly (p<0.05) negative & 144 & 10 & 381 \\
\hline
\end{tabular}

Source: Authors computation from www.finance.yahoo.com.

The results presented in this Subsection demonstrate that in opening trading sessions, stock prices tend to display a reverting behaviour following previous day's price tendencies. Such behaviour may be regarded as a kind of intraday price reversals, and seems to contradict market efficiency.

The basic idea in this respect is that during the trading day (continuous trading session), significant part of trades may be performed by noise traders. 4 According to the Efficient Markets Hypothesis, market agents should be unable to earn returns systematically in excess of equilibrium expected returns (Fama, 1976). Yet, many more recent studies argue that individual investor trading is often motivated by a variety of psychological heuristics and biases. For example, a combination of mental accounting (Thaler (1985)) and risk seeking in the domain of losses (Kahneman - Tversky, 1979) may lead investors to hold onto losing

4 Investors who make decisions regarding buy and sell trades based on different technical patterns, rather than on the use of the fundamental data. These investors generally have poor timing, follow trends, and over-react to good and bad news (e.g., Black, 1986, Shefrin - Statman, 1994, Kumar Lee, 2005). 
investments and sell winners. The representativeness heuristic (Tversky Kahneman, 1974) may lead investors to buy securities with strong recent returns because they view recent return patterns to be representative of the underlying distribution of returns (e.g., DeBondt - Thaler, 1987, DeBondt, 1993, Barberis et al., 1998). Overconfidence may cause investors to trade too aggressively and, in combination with self-attribution bias, could contribute to momentum in stock returns (e.g., Kyle - Wang, 1997, Odean, 1998, Daniel et al., 2001, Gervais Odean, 2001). Limited attention may constrain the set of stocks investors consider buying (Barber - Odean, 2008) causing purchases to be artificially concentrated in attention grabbing stocks. And the desire to avoid future regret may lead investors to repurchase stocks that have gone down in price since they were previously sold or purchased (Odean et al., 2011).

Individual investors play the role of noise traders in equity markets, and as demonstrated by Shleifer and Summers (1990), DeLong et al. (1990), DeLong et al. (1991), and Shleifer and Vishny (1997), noise traders may influence prices even in markets where some investors are well informed, because informed traders face risks that are likely to limit their actions. As a result, stock prices may systematically (temporarily) depart from their underlying values. A number of studies examine the relationship between aggregate individual investor buying and contemporaneous returns. Over a two-year period, Goetzmann and Massa (2003) establish a strong contemporaneous correlation between daily index fund inflows and S\&P 500 market returns. Kumar and Lee (2005) demonstrate a correlation in the aggregate buy-sell imbalance of individual investors at a large discount brokerage; these investors tend to move money into or out of the market at the same times as each other. Other studies test the implications of persistent buying (or selling) by individuals for subsequent, rather than contemporaneous, crosssectional returns. Hvidkjaer (2008) finds that stocks most actively purchased by individual investors in a given year tend to underperform in the following year. He detects evidence of continued underperformance for up to three years. Similarly, Barber et al. (2009) document that the stocks heavily bought during a given month systematically underperform those heavily sold for the next ten months.

In this context, the results of this study may be consistent with those by Hvidkjaer (2008) and Barber et al. (2009), but refer to much shorter time periods. The opento-close stock returns may be at least partially driven by noise traders' activity. As a result, closing stock prices may, at least for certain stocks depart from their underlying values. After the end of the trading day, when the stock prices remain unchanged, investors, especially information traders, may have a better possibility to analyse fundamental information and to discover price 'deviations', leading to the respective price 'corrections' right at the beginning of the next trading day. In other words, relatively high (low) open-to-close returns may be a result of noise trading, so that the respective stocks may underperform (outperform) in the next day's opening trading session. 


\subsection{Portfolios based on reversals in opening returns}

In order to test for practical applicability of the above results, I construct two portfolios based upon the idea of holding during the opening sessions and daily adjusting a long position in the stocks that according to the pattern documented in previous Subsection are expected to yield high opening returns, that is, the stocks that on the previous trading day showed relatively low open-to-close returns, and a short position in the stocks that according to the pattern are expected to yield low opening returns, that is, the stocks that on the previous trading day showed relatively high open-to-close returns. To get a proxy for the 'relatively' high (low) open-to-close returns, for each of the stocks and for each of the trading days, first I employ their sign, as in the previous Subsection, and alternatively, compare them to the respective day's general market (S\&P 500) open-to-close returns. The total values of the long and the short positions are supposed to be equal, that is, the total market value of each portfolio is supposed to be zero. I construct portfolios based on actual closing prices, assuming that open-to-close returns can be calculated and the transactions can be performed sufficiently close to the market closing time.

Portfolio N: Portfolio implying an equally-weighted long position for a day's opening session in the stocks whose previous day's open-to-close returns were Non-positive, and an equally-weighted short position for a day's opening session in the rest of the sample stocks. ${ }^{5}$

Portfolio M: Portfolio implying an equally-weighted long position for a day's opening session in the stocks whose previous day's open-to-close returns were smaller than the respective day's Market (S\&P 500) open-to-close return, and an equally-weighted short position for a day's opening session in the rest of the sample stocks.

Table 4 reports, over the sampling period, the basic daily performance measures for both portfolios. Strikingly, both portfolios yield positive and highly significant mean daily returns. These results, first of all, provide a strong support for my research hypothesis. That is, opening returns tend to be higher following the days characterized by relatively low open-to-close returns Moreover, from the practical point of view, if we deduct a $0.02 \%$ transaction fee for both buying and selling stocks, Portfolios $\mathrm{N}$ and $\mathrm{M}$ still yield positive and highly significant mean daily returns of $0.044 \%$ and $0.047 \%$, respectively, transforming to annual returns of about $12-13 \%$. Finally, if we look at the risk-return trade-off of the strategies, then we reveal that the Sharpe ratios for Portfolios $\mathrm{N}$ and $\mathrm{M}$, adjusted for the transaction costs, are 0.089 and 0.098 , respectively, compared to 0.027 and 0.037 , for the S\&P 500 daily and opening returns, respectively.

5 During the sampling period, there were no days when for all 500 stocks making up the index the open-to-close returns were either non-positive or non-negative. For each of the days, both the long and the short position are equally-weighted (notwithstanding the number of stocks making up the respective position), and their total values are equal. 
European Financial and Accounting Journal, 2015, vol. 10, no. 1, pp. 5-17.

Tab. 4: Historical performance measures of the portfolios based on the "overnight reversal" pattern in opening stock returns

Daily Portfolio/Index performance measures over the sampling period (5,289 days)

\begin{tabular}{|c|c|c|c|c|c|c|}
\hline \multirow[t]{2}{*}{ Statistics } & \multicolumn{2}{|c|}{$\begin{array}{l}\text { Before transaction } \\
\text { costs }\end{array}$} & \multicolumn{2}{|c|}{ After transaction costs } & \multicolumn{2}{|c|}{ S\&P 500} \\
\hline & $\begin{array}{c}\text { Portfolio } \\
\text { N }\end{array}$ & $\begin{array}{c}\text { Portfolio } \\
\text { M }\end{array}$ & $\begin{array}{c}\text { Portfolio } \\
\text { N }\end{array}$ & $\begin{array}{c}\text { Portfolio } \\
\text { M }\end{array}$ & Opening & Daily \\
\hline $\begin{array}{l}\text { Mean, in \% } \\
\text { Median, in \% } \\
\text { Standard Deviation, } \\
\text { in \% } \\
\text { Maximum, in \% } \\
\text { Minimum, in \% } \\
\end{array}$ & $\begin{array}{c}0.084 \\
0.071 \\
0.496 \\
10.351 \\
-9.859\end{array}$ & $\begin{array}{c}0.087 \\
0.074 \\
0.478 \\
8.125 \\
-7.025\end{array}$ & $\begin{array}{c}0.044 \\
0.031 \\
0.496 \\
10.311 \\
-9.899\end{array}$ & $\begin{array}{c}0.047 \\
0.034 \\
0.478 \\
8.085 \\
-7.065\end{array}$ & $\begin{array}{c}0.019 \\
0.021 \\
0.512 \\
9.657 \\
-8.251\end{array}$ & $\begin{array}{c}0.032 \\
0.058 \\
1.201 \\
11.580 \\
-9.035\end{array}$ \\
\hline $\begin{array}{l}\text { Sharpe Ratio } \\
\text { t-statistic }(\text { Mean=0) }\end{array}$ & $\begin{array}{c}\mathbf{0 . 1 6 9} \\
* * * 10.25\end{array}$ & $\begin{array}{c}\mathbf{0 . 1 8 2} \\
* * * 10.98\end{array}$ & $\begin{array}{c}\mathbf{0 . 0 8 9} \\
* * * 4.85\end{array}$ & $\begin{array}{c}\mathbf{0 . 0 9 8} \\
* * * 5.87\end{array}$ & $\begin{array}{c}0.037 \\
1.78\end{array}$ & $\begin{array}{c}0.027 \\
1.81\end{array}$ \\
\hline
\end{tabular}

Source: Authors computation from www.finance.yahoo.com.

Note: Asterisks denote two-tailed p-values: $* * * \mathrm{p}<0.01$.

Table 5 presents, for each of the 21 years of the sampling period, annual returns for both portfolios, both before and after transaction costs, and compares them to the annual S\&P 500 returns. The most striking observation is that even after deducting the transaction costs both portfolios consistently outperform the general market index for all the 21 years.

Tab. 5: Annual returns of the portfolios based on the "overnight reversal" pattern

\begin{tabular}{|c|c|c|c|c|c|}
\hline \multirow{3}{*}{ Year } & \multicolumn{5}{|c|}{ Portfolio/Index annual returns, in \% } \\
\hline & \multicolumn{2}{|c|}{ Before transaction costs } & \multicolumn{2}{|c|}{ After transaction costs } & \multirow{2}{*}{$\begin{array}{c}\text { S\&P } 500 \\
\text { daily }\end{array}$} \\
\hline & Portfolio N & Portfolio M & Portfolio N & Portfolio M & \\
\hline 1993 & 18.87 & 20.78 & 8.41 & 10.21 & 6.90 \\
\hline 1994 & 10.45 & 10.94 & -0.08 & 1.23 & -1.54 \\
\hline 1995 & 56.14 & 57.12 & 45.63 & 46.81 & 34.11 \\
\hline 1996 & 49.01 & 49.11 & 38.54 & 38.56 & 20.26 \\
\hline 1997 & 49.05 & 52.58 & 38.70 & 42.07 & 31.01 \\
\hline 1998 & 41.58 & 51.24 & 31.28 & 40.85 & 26.67 \\
\hline 1999 & 37.99 & 37.94 & 27.41 & 27.34 & 19.53 \\
\hline 2000 & 4.87 & 6.31 & -6.87 & -4.17 & -10.14 \\
\hline 2001 & 2.87 & 3.32 & -7.84 & -7.29 & -13.04 \\
\hline 2002 & -2.96 & -2.08 & -13.48 & -12.69 & -23.37 \\
\hline 2003 & 32.85 & 39.87 & 22.36 & 29.34 & 26.38 \\
\hline 2004 & 28.68 & 29.22 & 18.10 & 18.74 & 8.99 \\
\hline 2005 & 15.63 & 15.87 & 5.11 & 5.37 & 3.00 \\
\hline 2006 & 21.77 & 25.97 & 11.23 & 15.40 & 13.62 \\
\hline 2007 & 13.82 & 15.18 & 3.29 & 4.70 & 3.53 \\
\hline 2008 & -22.02 & -18.74 & -32.54 & -29.21 & -38.49 \\
\hline 2009 & 38.52 & 39.03 & 27.93 & 28.47 & 23.45 \\
\hline
\end{tabular}


Kudryavtsev A.: Informational Content of Open-to-Close Stock Returns.

\begin{tabular}{lllccc}
\hline 2010 & 33.21 & 35.45 & 22.77 & 24.91 & 12.78 \\
2011 & 10.72 & 12.03 & 0.12 & 1.84 & -0.03 \\
2012 & 26.66 & 27.48 & 16.23 & 16.97 & 13.41 \\
2013 & 45.61 & 47.71 & 35.10 & 37.29 & 29.60 \\
\hline
\end{tabular}

Source Authors computation from www.finance.yahoo.com.

\section{Conclusion}

The main goal of the present study is to shed light on the mechanism of interday correlations between open-to-close and opening stock returns. Following a wide strand of financial literature dealing with stock return autocorrelations, and extending the studies by Kudryavtsev $(2012,2013)$, which concentrate on the effect of the end-of-the-day significant ('extreme') stock price moves on the subsequent days' returns and document subsequent stock price reversals, I make an effort to establish if there also exist interday stock price reversals following some 'regular', rather than extreme, price changes. In this context, I suggest that relatively high (low) open-to-close returns may subsequently lead to relatively low (high) opening returns on the next trading day.

I analysed intraday price data on all the stocks making up the S\&P 500 Index during the period from January 4, 1993 to December 31, 2013, and found supporting evidence for my research hypothesis. I found that stock returns in opening trading sessions systematically tend to be higher following days with relatively low (either negative, or lower than the same day's market) open-to-close returns. Moreover, I explicitly documented that stock price tendencies reflected in open-to-close returns tend to be reversed during the opening session of the next trading day.

Finally, I tested if on the basis of these results it might be possible to define potentially profitable investment strategies. For the sampling period, I constructed two alternative daily-adjusted investment portfolios based on the opening trading sessions and involving a long position in the stocks on the days when, according to the findings, their opening returns are expected to be high and a short position in the stocks on the days when, according to the findings, their opening returns are expected to be low. Both portfolios, even after taking the trading commissions into consideration, are found to yield significantly positive returns, providing an evidence for the practical applicability of the documented pattern in opening stock prices.

To summarize, daily-adjusted strategies based on certain interday patterns in opening and open-to-close stock returns look promising. This may prove a valuable result for both financial theoreticians in their eternal discussion about stock market efficiency, and practitioners in search of potentially profitable investment strategies. Potential directions for further research may include considering investment strategies based on some other inter- and intraday return patterns and also expending the analysis to other stock exchanges. 


\section{References}

Amihud, Y., Mendelson, H., 1987. Trading Mechanisms and Stock Returns: An Empirical Investigation. Journal of Finance 42, 533-553.

Anderson, R. M., 2006. Time-Varying Risk Premia and Stock Return Autocorrelation, Working Paper, University of California at Berkeley.

Barber, B. M., Odean, T., 2008. All that Glitters: The Effect of Attention and News on the Buying Behavior of Individual and Institutional Investors. Review of Financial Studies 21, 785-818.

Barber, B. M., Odean, T., Zhu, N., 2009. Do Retail Traders Move Markets? Review of Financial Studies 22, 151-186.

Barberis, N., Shleifer, A., Vishny, R., 1998. A Model of Investor Sentiment. Journal of Financial Economics, 49, 307-343.

Black, F., 1986. Noise. Journal of Finance 41, 529-543.

Campbell, J. Y., Lo, A. W., MacKinlay, A. C., 1997. The Econometrics of Financial Markets. Princeton University Press, Princeton, NJ, 1997.

Chordia, T., Swaminathan, B., 2000. Trading Volume and Cross-Autocorrelations in Stock Returns. Journal of Finance 55, 913-935.

Daniel, K. D., Hirshleifer, D., Subrahmanyam, A., 2001. Overconfidence, Arbitrage, and Equilibrium Asset Pricing. Journal of Finance 56, 921-965.

DeBondt, W., 1993. Betting on Trends: Intuitive Forecasts of Financial Risk and Return. International Journal of Forecasting 9, 355-371.

DeBondt, W., Thaler, R., 1987. Further Evidence on Investor Overreaction and Stock Market Seasonality. Journal of Finance 42, 557-581.

DeLong, J. B., Shleifer, A., Summers, L. H., Waldmann, R. J., 1990. Noise Trader Risk in Financial Markets. Journal of Political Economy 98, 703-738.

DeLong, J. B., Shleifer, A., Summers, L. H., Waldmann, R. J., 1991. The Survival of Noise Traders in Financial Market. Journal of Business 64, 1-20.

Fama, E. F., 1976. Efficient Capital Markets: Reply. Journal of Finance 31, 143145.

Gervais, S., Odean, T., 2001. Learning to Be Overconfident. Review of Financial Studies 14, 1-27.

Goetzmann, W. N., Massa, M., 2003. Index Funds and Stock Market Growth. Journal of Business 76, 1-28.

Harris, L., 1986. A Transaction Data Study of Weekly and Intraday Patterns in Stock Returns. Journal of Financial Economy 16, 99-117.

Hvidkjaer, S., 2008. Small Trades and the Cross-Section of Stock Returns. Review of Financial Studies 21, 1123-1151. 
Kudryavtsev A.: Informational Content of Open-to-Close Stock Returns.

Jain, P. C., Joh, G. H., 1988. The Dependence between Hourly Prices and Trading Volume. Journal of Financial and Quantitative Analysis 23, 269-283.

Kahneman, D., Tversky, A., 1979. Prospect Theory: An Analysis of Decision under Risk. Econometrica 46, 171-185.

Kudryavtsev, A., 2012. Short-Term Stock Price Reversals May Be Reversed. International Journal of Economic Sciences and Applied Research 5, 129-146.

Kudryavtsev, A., 2013. Stock Price Reversals Following End-of-the-Day Price Moves. Economics Letters 118, 203-205.

Kumar, A., Lee, C. M., 2005. Retail Investor Sentiment and Return Comovements, SSRN Working Paper, Available from: 〈http://ssrn.com/abstract=502843〉.

Kyle, A., Wang, F. A., 1997. Speculation Duopoly with Agreement to Disagree: Can Overconfidence Survive the Market Test? Journal of Finance 52, 2073-2090.

Lo, A. W., MacKinlay, A. C., 1990. An Econometric Analysis of Nonsynchronous Trading. Journal of Econometrics 45, 181-212.

Odean, T., 1998. Volume, Volatility, Price, and Profit When All Traders are Above Average. Journal of Finance 53, 1887-1934.

Odean, T., Strahilevitz, M., Barber, B. M., 2011. Once Burned, Twice Shy: How Naïve Learning and Counterfactuals Affect the Repurchase of Stocks Previously Sold. Journal of Marketing Research 48, 102-120.

Pagano, M. S., Peng, L., Schwartz, R. A., 2008. The Quality of Price Formation at Market Openings and Closings: Evidence from the NASDAQ Stock Market, Working paper, Villanova University.

Rhee, S. G., Wang, C. J., 1997. The Bid-Ask Bounce Effect and the Spread Size Effect: Evidence from the Taiwan Stock Market. Pacific-Basin Finance Journal 5, 231-258.

Shefrin, H., Statman, M., 1994. Behavioral Capital Asset Pricing Theory. Journal of Financial and Quantitative Analysis 29, 323-349.

Shleifer, A., Summers, L., 1990. The Noise Trader Approach to Finance. Journal of Economic Perspectives 4, 19-33.

Shleifer, A., Vishny, R., 1997. The Limits of Arbitrage. Journal of Finance 52, no. 1, 35-55.

Sias, R. W., Starks, L. T., 1997. Return Autocorrelation and Institutional Investors. Journal of Financial Economics 46, 103-131.

Stoll, H. R., Whaley, R. E., 1990. Stock Market Structure and Volatility. Review of Financial Studies 3, 37-71.

Thaler, R., 1985. Mental Accounting and Consumer Choice. Marketing Science 4, 199-214. 
European Financial and Accounting Journal, 2015, vol. 10, no. 1, pp. 5-17.

Tversky, A., Kahneman, D., 1974. Judgment under Uncertainty: Heuristics and Biases. Science 185, 1124-1131.

Wood, R. A.,, McInish, T. H., Ord, J. K., 1985. An Investigation of Transactions Data for NYSE Stocks. Journal of Finance 40, 723-739. 
